\title{
Real Power Loss Reduction by Blue Noddy and European Night Crawler Optimization Algorithms
}

\author{
Lenin Kanagasabai \\ Department of EEE, Prasad V.Potluri Siddhartha Institute of Technology \\ Kanuru, Vijayawada, Andhra Pradesh -520007, India \\ E-mail: gklenin@gmail.com
}

Keywords: optimal reactive power, transmission loss, blue noddy, European night crawler

Received: January 6, 2021

\begin{abstract}
In this paper Blue noddy optimization (BNO) algorithm and European Night crawler optimization (ENO) algorithm are applied to solve the power loss reduction problem. Key objective is to reduce the power loss with voltage stability enhancement and minimization of voltage deviation. Exodus and Preying behaviour of the Blue noddy has been imitated to formulate the algorithm. In the mathematical formulation of Exodus deed - collusion between the Blue noddy has been avoided and blue noddy will converge in the direction of most excellent companion. Position update of the Blue noddy is based on the most excellent explore agent. Preying behaviour is based on the line and angle of preying. Logically the angle, velocity will be transformed by the Blue noddy and it will do spiral act in the air to seizure the prey. Exploration and Exploitation is augmented through the Exodus and preying behaviour. In ENO algorithm reproduction nature of the European Night crawler is imitated to design the algorithm. European Night crawler population is created through the off-springs with two different kinds of reproduction. The dimension of the adolescent European Night crawler is alike to the parent. In the method Cross over operation has been implemented by considering the parent European Night crawler and Cauchy mutation has been included in order to elude the solution to be trapped under local optima. With and without voltage stability ( $L$-index) proposed BNO and ENO algorithms are verified in IEEE 30 Bus system. Active power loss reduction has been achieved with L-index improvement and voltage deviation minimized.
\end{abstract}

Povzetek: V tem prispevku sta za reševanje problema zmanjšanja izgube energije uporabljena algoritem $B N O$ za optimizacijo in algoritem ENO (European Night crawler optimization).

\section{Introduction}

Active power loss reduction is an important problem in Electrical power system. Many methodologies from conventional techniques; Newton, successive quadratic programming, linear programming, interior point (Abril et al., Bjelogrlic et al., Granville, Grudinin, Edalatpanah et al., ) [1-5] to evolutionary and swarm based algorithms; Ant colony, Fish swarm, Frog leaping, Wolf search, Bacterial foraging, Whale optimization, Marine Predators Algorithm, harmony search algorithm (Ebeed et al., Li, Jian et al., Yasir Muhammad et al., Barakat et al., Sahli et al., Mouassa et al., Mandal et al., Khazali et al., Tran et al., ) [6-10] are chronologically applied to solve the problem. Yet various factors are influenced in the poor performance of the techniques. In conventional methods inequality constraints are unable to be included successfully and in evolutionary based algorithms balancing the exploration and exploitation are major task to reach the most excellent solution [11-18]. There should be proper trade-off between exploration and exploitation because when trade-off failed then it not at all possible to reach a better solution [21-25]. This paper proposes Blue noddy optimization (BNO) algorithm and European Night crawler optimization (ENO) algorithm for power loss reduction. Main objective is to reduce the power loss reduction with voltage stability enhancement and Voltage deviation minimization. Blue noddy is extensively dispersed across the Pacific. They feed nearby the shore and capture the fishes and other insects. Naturally Blue noddy possesses the Exodus and Preying behaviour. With respect to seasonal variations Blue noddy will execute the Exodus actions in exploration of food and Blue noddy will apply its intelligence while preying. These two actions has been imitated and modelled to solve the problem. Exploration and exploitation has been balanced through the phases of Exodus and Preying. Preying behaviour of the Blue noddy is mathematically formulation based on the line and angle of preying. Unsurprisingly the angle, velocity will be reformed by the Blue noddy and it will do the spiral performance in the air for detention of the prey. Then in this paper European Night crawler optimization (ENO) algorithm is applied to solve the problem. ENO algorithm has been designed based on the normal actions of European Night crawler. Reproduction nature of the European Night crawler is imitated to design the algorithm. European Night crawler population is created 
through the off-springs with two different kinds of reproduction. The dimension of the adolescent European Night crawler is alike to the parent. In the procedure when an individual European Night crawler possess the premium fitness then it will pass to the subsequent generation without any modification. In the process Cauchy mutation has been included in order the evade the solution to be trapped under local optima Validity of the Proposed Blue noddy optimization (BNO) algorithm and European Night crawler optimization (ENO) algorithm has been verified in IEEE 30 Bus system by considering L-index (Voltage stability). Then both the BNO and ENO algorithms are evaluated without considering L-index. Power loss reduction has been attained with L-index enhancement and voltage deviation minimized. Mainly percentage of power loss reduction is improved.

\section{Problem formulation}

Power loss minimization is defined by

Min $\widetilde{O B F}(\bar{r}, \bar{u})$

Subject to

$L(\bar{r}, \bar{u})=0$

$M(\bar{r}, \bar{u})=0$

$r=\left[V L G_{1}, \ldots, V L G_{N g} ; Q C_{1}, \ldots, Q C_{N c} ; T_{1}, \ldots, T_{N_{T}}\right]$

$u$

$=\left[P G_{\text {slack }} ; V L_{1}, \ldots, V L_{N_{\text {Load }}} ; Q G_{1}, \ldots, Q G_{N g} ; S L_{1}, \ldots, S L_{N_{T}}\right]$

The fitness function $\left(F_{1}, F_{2}, F_{3}\right)$ is designed for power loss (MW) reduction, Voltage deviation, voltage stability index (L-index) is defined by,

$F_{1}=P_{\text {Minimize }}=$ Minimize $\left[\sum_{m}^{N T L} G_{m}\left[V_{i}^{2}+V_{j}^{2}-2 *\right.\right.$ $\left.\left.V_{i} V_{j} \cos \emptyset_{i j}\right]\right]$

$F_{2}=$ Minimize $\left[\sum_{i=1}^{N_{L B}}\left|V_{L k}-V_{L k}^{\text {desired }}\right|^{2}+\sum_{i=1}^{N g} \mid Q_{G K}-\right.$

$\left.\left.Q_{K G}^{\operatorname{Lim}}\right|^{2}\right]$

$F_{3}=$ Minimize $L_{\text {MaxImum }}$

$L_{\text {Maximum }}=\operatorname{Maximum}\left[L_{j}\right] ; j=1 ; N_{L B}$

And $\left\{\begin{array}{c}L_{j}=1-\sum_{i=1}^{N P V} F_{j i} \frac{V_{i}}{V_{j}} \\ F_{j i}=-\left[Y_{1}\right]^{1}\left[Y_{2}\right]\end{array}\right.$

$L_{\text {Maximum }}=$ Maximum $\left[1-\left[Y_{1}\right]^{-1}\left[Y_{2}\right] \times \frac{v_{i}}{V_{j}}\right]$

Equality constraints

$0=P G_{i}-P D_{i}-V_{i} \sum_{j \in N_{B}} V_{j}\left[G_{i j} \cos \left[\varnothing_{i}-\varnothing_{j}\right]+\right.$

$\left.B_{i j} \sin \left[\varnothing_{i}-\varnothing_{j}\right]\right]$

$0=Q G_{i}-Q D_{i}-V_{i} \sum_{j \in N_{B}} V_{j}\left[G_{i j} \sin \left[\varnothing_{i}-\varnothing_{j}\right]+\right.$

$\left.B_{i j} \cos \left[\varnothing_{i}-\varnothing_{j}\right]\right]$

Inequality constraints

$$
\begin{gathered}
\mathrm{P}_{\text {gslack }}^{\text {minimum }} \leq \mathrm{P}_{\text {gslack }} \leq \mathrm{P}_{\text {gslack }}^{\text {maximum }} \\
\mathrm{Q}_{\mathrm{gi}}^{\text {minimum }} \leq \mathrm{Q}_{\mathrm{gi}} \leq \mathrm{Q}_{\mathrm{gi}}^{\text {maximum }}, \mathrm{i} \in \mathrm{N}_{\mathrm{g}} \\
\mathrm{VL}_{\mathrm{i}}^{\text {minimum }} \leq \mathrm{VL}_{\mathrm{i}} \leq \mathrm{VL}_{\mathrm{i}}^{\text {maximum }}, \mathrm{i} \in \mathrm{NL}
\end{gathered}
$$

$$
\begin{gathered}
\mathrm{T}_{\mathrm{i}}^{\text {minimum }} \leq \mathrm{T}_{\mathrm{i}} \leq \mathrm{T}_{\mathrm{i}}^{\text {maximum }}, \mathrm{i} \in \mathrm{N}_{\mathrm{T}} \\
\mathrm{Q}_{\mathrm{c}}^{\text {minimum }} \leq \mathrm{Q}_{\mathrm{C}} \leq \mathrm{Q}_{\mathrm{C}}^{\text {maximum }}, \mathrm{i} \in \mathrm{N}_{\mathrm{C}} \\
\left|S L_{\mathrm{i}}\right| \leq S_{L_{i}}^{\text {maximum }}, \mathrm{i} \in \mathrm{N}_{\mathrm{TL}} \\
\mathrm{VG}_{\mathrm{i}}^{\text {minimum }} \leq \mathrm{VG}_{\mathrm{i}} \leq \mathrm{VG}_{\mathrm{i}}^{\text {maximum }}, \mathrm{i} \in \mathrm{N}_{\mathrm{g}}
\end{gathered}
$$

Multi objective fitness (MOF) function has been defined by,

$$
\begin{aligned}
& M O F=F_{1}+r_{i} F_{2}+u F_{3}=F_{1}+\left[\sum _ { i = 1 } ^ { N L } x _ { v } \left[V L_{i}-\right.\right. \\
& \left.\left.V L_{i}^{\text {min }}\right]^{2}+\sum_{i=1}^{N G} r_{g}\left[Q G_{i}-Q G_{i}^{\text {min }}\right]^{2}\right]+r_{f} F_{3} \\
& V L_{i}^{\text {minimum }}=\left\{\begin{array}{l}
V L_{i}^{\text {max }}, V L_{i}>V L_{i}^{\text {max }} \\
V L_{i}^{\text {min }}, V L_{i}<V L_{i}^{\text {min }}
\end{array}\right. \\
& Q G_{i}^{\text {minimum }}=\left\{\begin{array}{c}
Q G_{i}^{\text {max }}, Q G_{i}>Q G_{i}^{\text {max }} \\
Q G_{i}^{\text {min }}, Q G_{i}<Q G_{i}^{\text {min }}
\end{array}\right.
\end{aligned}
$$

\section{Blue noddy optimization algorithm}

Blue noddy is sea bird and its natural actions are imitated to formulate the algorithm. Movement of the Blue noddy during Exodus will be in a group mode. Naturally collusion will be avoided while their movement and with respect to the lead Blue noddy others will adjust the position. Direction will be based on the most excellent conditions. These behaviors are imitated and modeled in the Exodus behavior of the Blue noddy.

During the Exodus, Collusion will be evaded between them and it has been mathematically formulated as follows,

Collusion explore agent $\left(C n_{\text {ea }}\right)=$

Blue noddy $y_{\text {agent }}\left(B n_{a}\right) \times$

Current position serach agent $\left(C p_{s a}\right)$.

(Current iteration $(\mathrm{Ci})$ )

Then the movement of the $B n_{a}$ in the exploration phase is given by,

$$
B n_{a}=\text { Direction variable }\left(D v_{f}\right)-(C i \times
$$

$\left(\right.$ Dv $_{f} /$ Maximum $\left.\left._{\text {iterations }}\right)\right)$

Naturally the blue noddy will converge in the direction of most excellent companion Blue noddy and it has been mathematically formulated as follows,

Different locations of explore agent $\left(D l_{e a}\right)=$ Random variable $\left(R v_{e l}\right) \times$ (most excellent fittest search agent $\left(C p_{m s a}\right)$. $(C i)-$ Current position serach agent $\left(C p_{s a}\right)$.

(Current iteration $(\mathrm{Ci})$ )

In the above equation Random variable $\left(R v_{e l}\right)$ is accountable for enhanced exploration.

Random variable $\left(R v_{e l}\right)=0.50 \times$

Random number $\left(R_{n r}\right) ; R_{n r} \in[0,1]$

Blue noddy will update its Position based on the most excellent explore agent and it mathematically formulated as follows,

Space between explore agent and most excellent fittest explore agent $\left(S_{s a}\right)$

$$
\begin{aligned}
& =\text { Collusion explore agent }\left(C n_{e a}\right) \\
& + \text { Different locations of }
\end{aligned}
$$


explore agent $\left(D l_{e a}\right)$

Preying behaviour of the Blue noddy is mathematically formulation based on the line and angle of preying. Naturally the angle, velocity will be altered by the Blue noddy and it will do spiral performance in the air to capture the prey. This preying behaviour will amplify the Exploitation behaviour of the algorithm and it mathematically formulated as follows,

$$
\begin{aligned}
& X=\operatorname{Axis} \times \operatorname{Sin}(i) \\
& Y=\operatorname{Axis} \times \operatorname{Cos}(i) \\
& Z=A x i s \times i \\
& a=p \times e^{k q}
\end{aligned}
$$

Where axis indicates the every shot of the spiral performance, " $i$ " indicates the variables in the range of $0 \leq k \leq 2 \pi$ with $\mathrm{p}$ and $\mathrm{q}$ (constants).

Then the position of the other explore agents are defined as follows,

Position of other explore agents $\left(\mathrm{Po}_{\text {ea }}\right)$

- Current iteration ( $\mathrm{Ci}$ )

$$
=\left(\begin{array}{c}
\text { pace between explore agent } \\
\text { and most excellent } \\
\text { fittest explore agent }\left(S_{s a}\right) \times(X+Y+Z)
\end{array}\right)
$$$$
\times \text { most excellent fittest search }
$$$$
\text { agent }\left(C p_{m s a}\right) \cdot \text { Current iteration (Ci) (33) }
$$

a. Start

b. Engender the population

c. Initialization of parameters

d. Compute the fitness value for every explore agent

e. $\quad C p_{\text {msa }} \leftarrow$ best explore agent

f. While (Current iteration $(\mathrm{Ci})<$ Maximum $_{\text {iterations }}$ do)

g. For very explore agent do

h. Position of every explore agent is updated

$$
\begin{aligned}
& P o_{e a} \cdot C i=\left(\left(S_{s a}\right) \times(X+Y+Z)\right)\left(C p_{m s a}\right) . \\
& (C i)
\end{aligned}
$$

i. End for

j. Update the value of Collusion explore agent $\left(C n_{e a}\right)$ and Random variable $\left(R v_{e l}\right)$

k. Compute the fitness value for every explore agent

1. If improved solution is existing then update

most excellent fittest search agent $\left(C p_{m s a}\right)$

m. $C i \leftarrow C i+1$

n. End while

o. Yield the $C p_{m s a}$

p. End

\section{European night crawler optimization algorithm}

European Night crawler optimization (ENO) algorithm has been designed based on the natural actions of European Night crawler. Reproduction nature of the European Night crawler is imitated to model the algorithm. Population generation of the European Night crawler is through the off-springs with two different kinds of reproduction. The length of the adolescent European Night crawler is similar to the parent. In the process- when an individual European Night crawler possess the most excellent fitness then it will pass to the subsequent generation without any alteration.

Generally European Night crawler possesses both male and female sex organs and it can produce the adolescent European Night crawler by itself. Mathematical formulation of the above approach can be defined as,

$$
E n_{i 1, j}=E n_{\text {maximum }, j}+E_{\text {minimum }, j}-\alpha E n_{i, j} ; \alpha \in
$$

Where $E n_{i 1, j}$ the jth element of the European Night crawler and factor is $\alpha$ determines the distance between the parent and offspring

Cross over operation has been implemented by considering the parent European Night crawler as $P_{E n}=$ 2 and adolescent European Night crawler as $A_{E n}=1$. Then two parent European Night crawler $P_{E n} 1$ and $P_{E n} 2$ are chosen by roulette wheel selection method and it mathematically expressed as,

$$
P_{E n}=\left[\begin{array}{l}
P_{E n_{1}} \\
P_{E n_{2}}
\end{array}\right]
$$

Then "2" off-springs $E n_{12}$ and $E n_{22}$ are produced from the " 2 " parents and it defined as,

$$
\text { If random }>0.50, E n_{12, j}=P_{E n_{1, j}} \text { and } E n_{22, j}=
$$$$
P_{E n_{2, j}}
$$

Or else

$$
E n_{12, j}=P_{E n_{2, j}} \text { and } E n_{22, j}=P_{E n_{1, j}}
$$

Then $E n_{i 2}$ is defined as,

$$
E n_{i 2}=\left\{\begin{array}{c}
E n_{12} \text { for random }_{1}<0.50 \\
E n_{22} \quad \text { otherwise }
\end{array}\right.
$$

The next generation European Night crawler $\left(E n_{i}^{\prime}\right)$ is defined after the generation of $E n_{i 1}$ and $E n_{i 2}$

$E n_{i}^{\prime}=\beta E n_{i 1}+(1-\beta) E n_{i 2}$

Through the factor ' $\beta$ ' proportion between $E n_{i 1}$ and $E n_{i 2}$ is adjusted by balancing the global and local search effectively.

$\beta^{c t+1}=\gamma \cdot \beta^{c t}$

Where "ct" is the existing generation and in the preliminary stage $c t=0$ and $\beta=1$

In the procedure Cauchy mutation has been included in order to avoid the solution to be trapped under local optima and it has been defined as,

$$
\text { weight }_{j}=\left(\sum_{i=1}^{N \text { population }} E n_{i, j}\right) / N \text { population }
$$

Then the jth element of the last European Night crawler is defined as

$$
\begin{gathered}
E n_{i, j}^{\prime \prime}=E n_{i, j}^{\prime}+\left(\text { weight }_{j}=\right. \\
\left.\left(\sum_{i=1}^{N \text { population }} E n_{i, j}\right) / N \text { population }\right) * G
\end{gathered}
$$

Where " $G$ " is the random number and it haggard from the Cauchy distribution $\tau=$ 1 where $\tau$ scale parameter
a. Start
b. Initialization of parameters
c. Engender the population of European Night crawler 
d. Feasibility and Deception of the European Night crawler population to be checked

e. Compute the value of the objective function

f. Arrange the obtained values of objective function in ascending order

g. Find the most excellent population

h. Save the most excellent population ('N')

i. Engender the offs-springs through reproduction

j. Produce the off-springs by including the cross over operation

k. Obtain the New-fangled European Night crawler by the weighted summation of two offsprings

1. Apply Cauchy mutation to the New-fangled European Night crawler to acquire the last European Night crawler for subsequent generation

m. New-fangled population's feasibility is checked

n. Repeat the steps "I" to " $m$ " until definite number of population reached

o. Repeat the step " $\mathrm{f}$ '

p. Poor population are replaced by most excellent population

q. Repeat the steps "d", "e" and "f"

r. Repeat the steps form "g" to " $h$ " until finest solution obtained

s. End

\section{Simulation study}

Projected Blue noddy optimization (BNO) algorithm and European Night crawler optimization (ENO) algorithm has been tested in standard IEEE 30 bus system [20]. In Table 1 shows the loss comparison, Table 2 shows the voltage deviation comparison and Table 3 gives the Lindex comparison. Figures - 1to 3 gives the graphical comparison between the methodologies with reference to power loss, voltage stability improvement, voltage deviation.

Then Projected Blue noddy optimization (BNO) algorithm and European Night crawler optimization (ENO) algorithm verified in IEEE 30 bus test system [19] without considering voltage stability (L- index). Loss comparison is shown in Table 4 . Figure 4 gives graphical comparison between the methodologies with reference to power loss.

Table 5 shows the convergence characteristics of the Blue noddy optimization (BNO) algorithm and European Night crawler optimization (ENO) algorithm. Figure 5 shows the graphical representation of the characteristics. Blue noddy optimization (BNO) algorithm and European Night crawler optimization (ENO) algorithm reduced the power loss efficiently. Comparison of loss has been done with PSO, modified PSO, improved PSO, comprehensive learning PSO, Adaptive genetic algorithm, Canonical genetic algorithm, enhanced genetic algorithm, Hybrid PSO-Tabu search (PSO-TS), Ant lion (ALO), quasioppositional teaching learning based (QOTBO), improved stochastic fractal search optimization algorithm (ISFS), harmony search (HS), improved pseudo-gradient search particle swarm optimization and cuckoo search

\begin{tabular}{|l|l|}
\hline Method & Power loss (MW) \\
\hline BPSO-TS [10] & 4.5213 \\
\hline TS [10] & 4.6862 \\
\hline BPSO [10] & 4.6862 \\
\hline ALO [11] & 4.5900 \\
\hline QO-TLBO [12] & 4.5594 \\
\hline TLBO [12] & 4.5629 \\
\hline SGA [13] & 4.9408 \\
\hline BPSO [13] & 4.9239 \\
\hline HAS [13] & 4.9059 \\
\hline S-FS [14] & 4.5777 \\
\hline IS-FS [14] & 4.5142 \\
\hline SFS [16] & 4.5275 \\
\hline BNO & 4.5012 \\
\hline ENO & 4.5010 \\
\hline
\end{tabular}

Table 1: Comparison of Real power loss for IEEE 30 bus system.

\begin{tabular}{|l|l|}
\hline Method & Voltage deviation (PU) \\
\hline BPSO-TVIW [15] & 0.1038 \\
\hline BPSO-TVAC [15] & 0.2064 \\
\hline SPSO-TVAC [15] & 0.1354 \\
\hline BPSO-CF [15] & 0.1287 \\
\hline PG-PSO [15] & 0.1202 \\
\hline SWT-PSO [15] & 0.1614 \\
\hline PGSWT-PSO [15] & 0.1539 \\
\hline MPG-PSO [15] & 0.0892 \\
\hline QO-TLBO [12] & 0.0856 \\
\hline TLBO [12] & 0.0913 \\
\hline S-FS [14] & 0.1220 \\
\hline ISFS [14] & 0.0890 \\
\hline SFS [16] & 0.0877 \\
\hline BNO & 0.0865 \\
\hline ENO & 0.0863 \\
\hline
\end{tabular}

Table 2: Comparison of voltage deviation for IEEE 30 bus system.

\begin{tabular}{|l|l|}
\hline Method & L-index (PU) \\
\hline BPSO-TVIW [15] & 0.1258 \\
\hline BPSO-TVAC [15] & 0.1499 \\
\hline SPSO-TVAC [15] & 0.1271 \\
\hline BPSO-CF [15] & 0.1261 \\
\hline PG-PSO [15] & 0.1264 \\
\hline SWT-PSO [15] & 0.1488 \\
\hline PGSWT-PSO [15] & 0.1394 \\
\hline MPG-PSO [15] & 0.1241 \\
\hline QO-TLBO [12] & 0.1191 \\
\hline TLBO [12] & 0.1180 \\
\hline ALO [11] & 0.1161 \\
\hline ABC [11] & 0.1161 \\
\hline GWO [11] & 0.1242 \\
\hline BA [11] & 0.1252 \\
\hline S-FS [14] & 0.1252 \\
\hline IS-FS [14] & 0.1245 \\
\hline SFS [16] & 0.1007 \\
\hline BNO & 0.1002 \\
\hline ENO & 0.1000 \\
\hline
\end{tabular}

Table 3: Comparison of Voltage stability index for IEEE 30 bus system. 


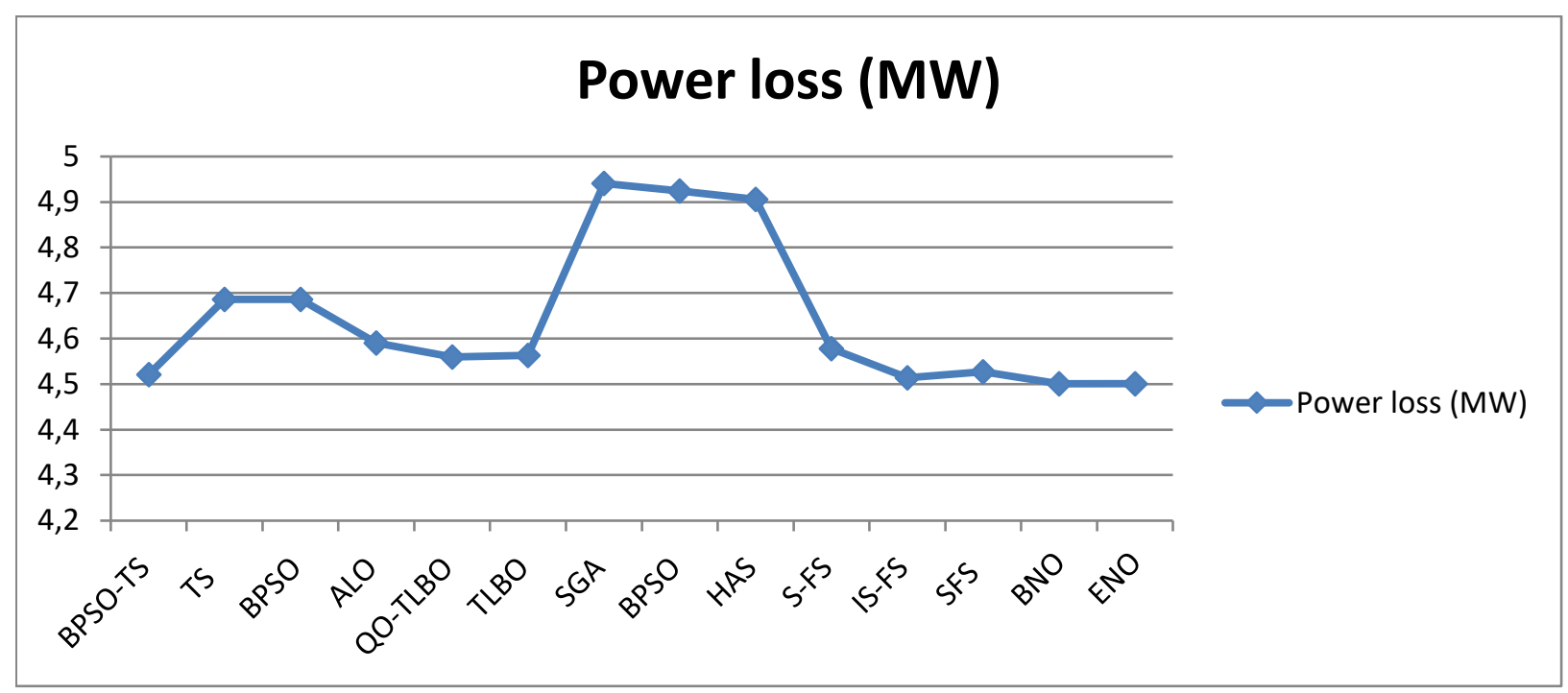

Figure 1: Comparison of real power loss.

\section{L-index (PU)}

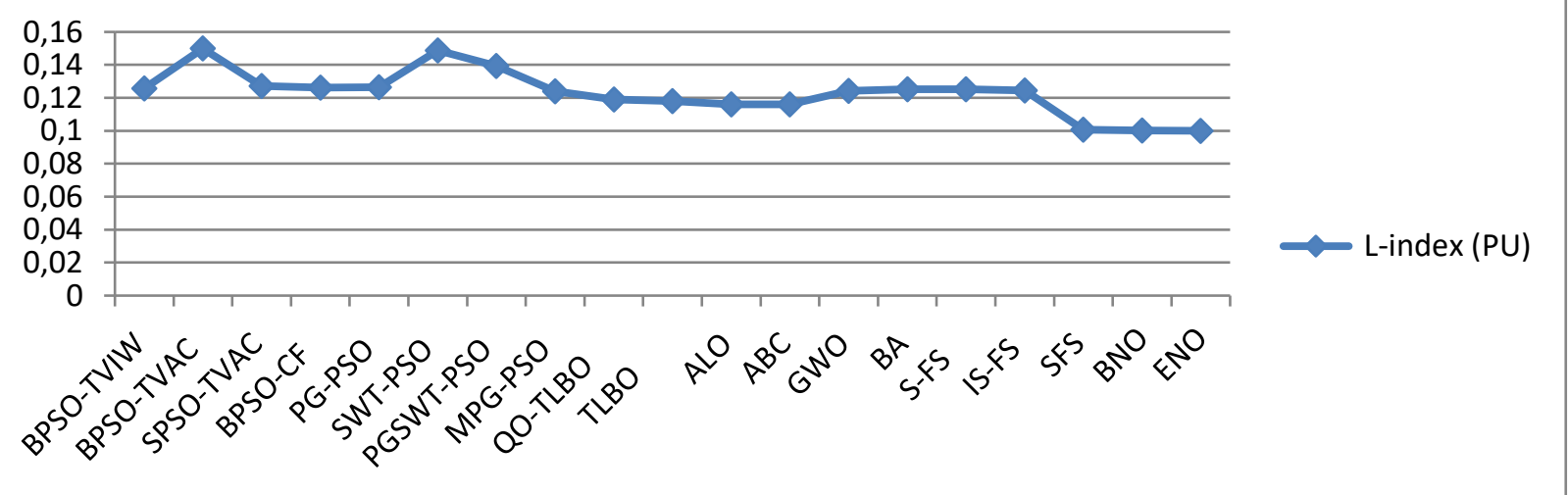

Figure 2: Comparison of voltage stability index.

\section{Voltage deviation (PU)}

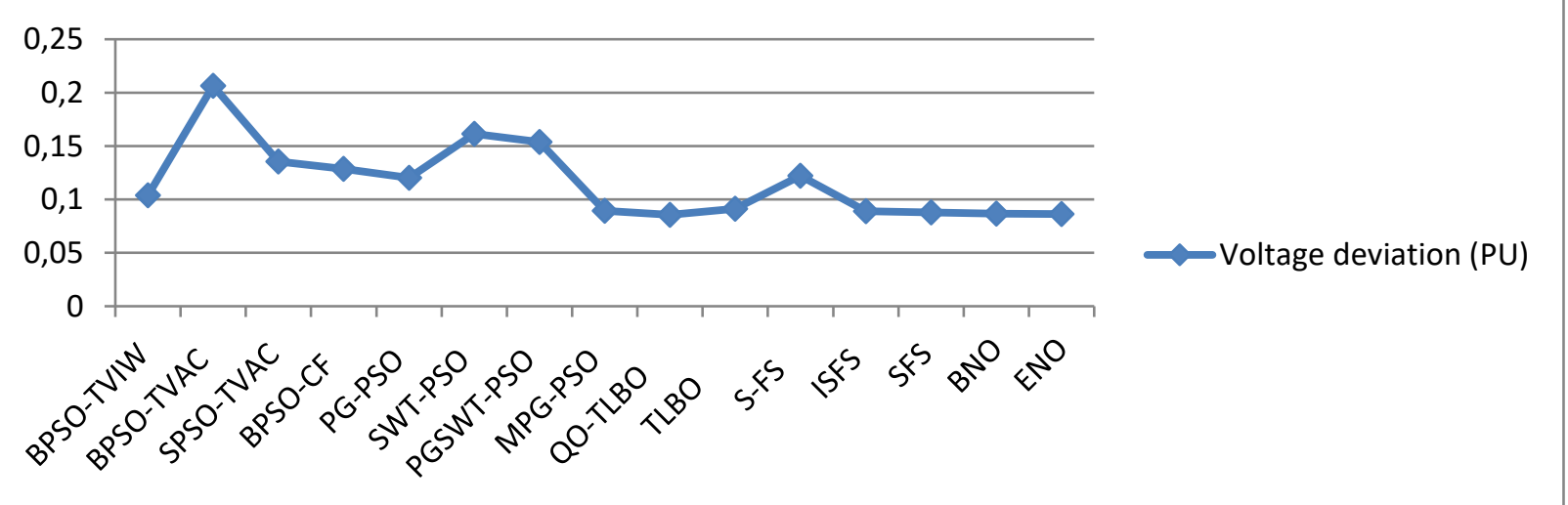

Figure 3: Comparison of Voltage deviation.

algorithm. Power loss reduced efficiently and percentage of the power loss reduction has been improved. Mainly voltage stability enhancement achieved with minimized voltage deviation. 


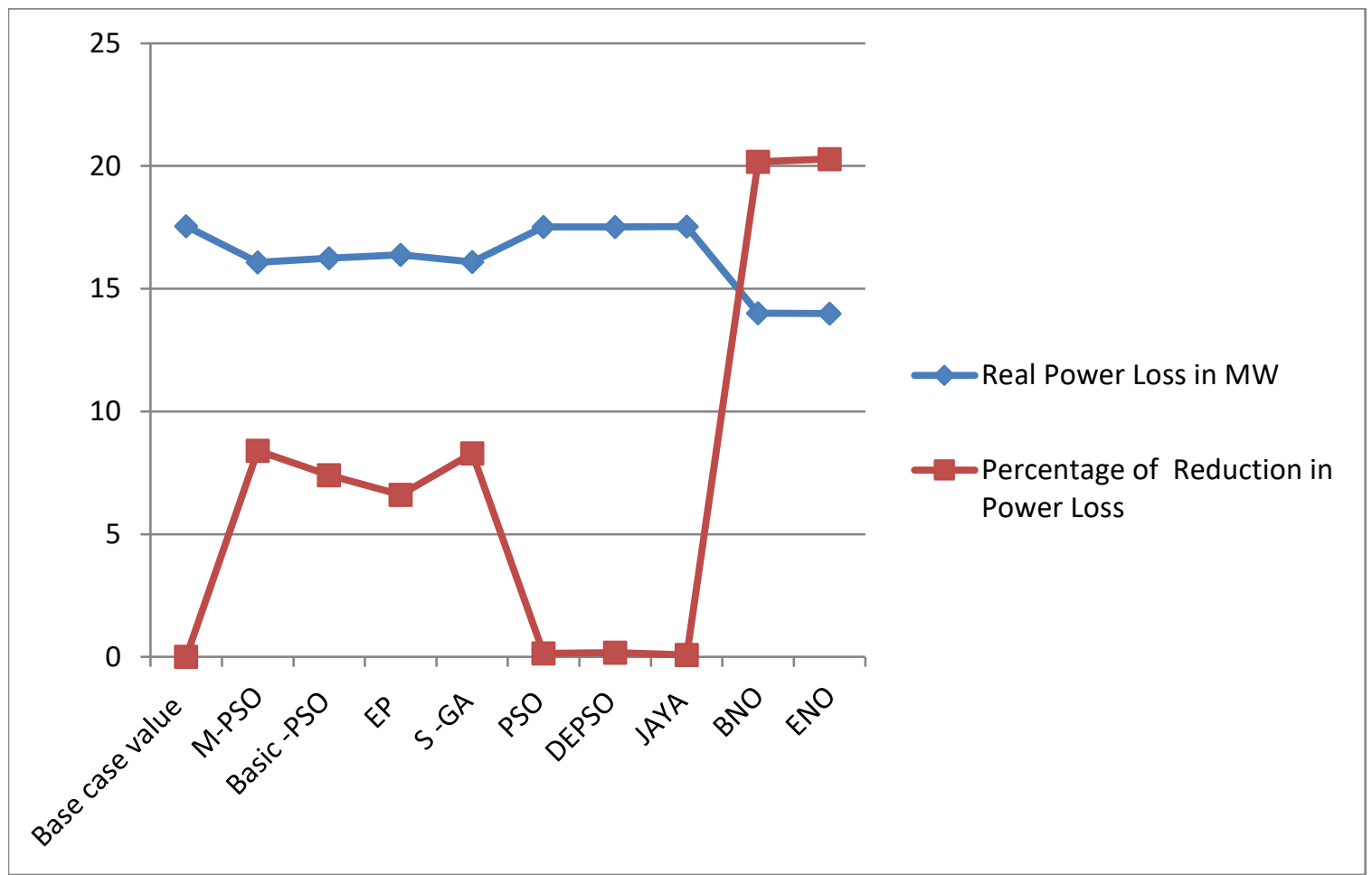

Figure 5: Comparison of Real Power Loss between methodologies (Tested in IEEE 30 bus system).

\begin{tabular}{|l|l|l|l|l|l|l}
\hline $\begin{array}{l}\text { IEEE } \\
\text { 30 Bus } \\
\text { system }\end{array}$ & $\begin{array}{l}\text { Real power } \\
\text { Loss in MW } \\
\text { (With L-index) }\end{array}$ & $\begin{array}{l}\text { Real power Loss } \\
\text { in MW (without } \\
\text { L-index) }\end{array}$ & $\begin{array}{l}\text { Time in Sec } \\
\text { (with L-index) }\end{array}$ & $\begin{array}{l}\text { Time in sec } \\
\text { (without L- } \\
\text { index) }\end{array}$ & $\begin{array}{l}\text { Number of } \\
\text { iterations } \\
\text { (with L-index) }\end{array}$ & $\begin{array}{l}\text { Number of } \\
\text { iterations (withou } \\
\text { L-index) }\end{array}$ \\
\hline BNO & 4.5012 & 14.01 & 18.09 & 16.16 & 19 & 16 \\
\hline ENO & 4.5010 & 13.989 & 17.99 & 15.91 & 17 & 15 \\
\hline
\end{tabular}

Table 4: Convergence characteristics.

\begin{tabular}{|l|l|l|}
\hline Parameter & $\begin{array}{l}\text { Real Power Loss } \\
\text { in MW }\end{array}$ & $\begin{array}{l}\text { Percentage of } \\
\text { Reduction in } \\
\text { Power Loss }\end{array}$ \\
\hline $\begin{array}{l}\text { Base case value } \\
{[24]}\end{array}$ & 17.5500 & 0.0000 \\
\hline M-PSO[24] & 16.0700 & 8.40000 \\
\hline Basic -PSO [23] & 16.2500 & 7.4000 \\
\hline EP [21] & 16.3800 & 6.60000 \\
\hline S -GA [22] & 16.0900 & 8.30000 \\
\hline PSO [25] & 17.5246 & 0.14472 \\
\hline DEPSO [25] & 17.52 & 0.17094 \\
\hline JAYA [25] & 17.536 & 0.07977 \\
\hline BNO & 14.01 & 20.17 \\
\hline ENO & 13.989 & 20.29 \\
\hline
\end{tabular}

Table 5: Comparison of loss with reference to IEEE -30 system.

\section{Conclusion}

Blue noddy optimization (BNO) algorithm and European Night crawler optimization (ENO) algorithm condensed the power loss with escalation of voltage stability. In BNO Exodus and Preying behavior of blue noddy has been imitated to formulate the algorithm. Blue noddy congregated in the direction of most excellent companion

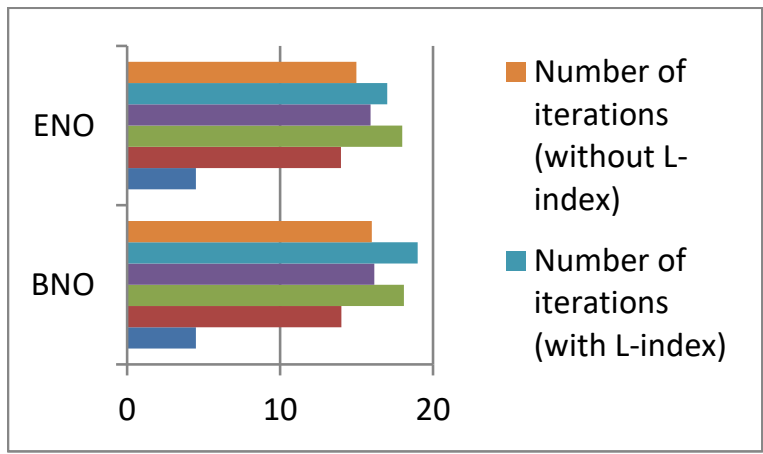

Figure 4: Convergence characteristics.

and Position updating is done based on the most excellent explore agent. In preying behaviour angle, velocity is altered by the Blue noddy and spiral performance done in the air to confiscation of the prey. Both Exodus and Preying phases will amplify the exploration and exploitation in the procedure of the algorithm. In ENO algorithm population generation of the European Night crawler is through the off-springs with two different kinds of reproduction. The length of the young European Night crawler is analogous to the parent. In the process - when an individual European Night crawler possess the most excellent fitness then it passed to the successive generation without any 
variation. Blue noddy optimization (BNO) algorithm and European Night crawler optimization (ENO) algorithm is verified in IEEE 30 - bus test system with Lindex and devoid of L-index. Both algorithms commendably reduced the power loss and percentage of real power loss lessening has been improved. Convergence characteristics show the better performance of the proposed BNO and ENO optimization algorithms. Comparison of power loss has been done with other standard reported algorithms. Percentage of real power loss reduction of BNO and ENO is 20.17, 20.29.

\section{Scope of future work}

In future proposed Blue noddy optimization (BNO) algorithm and European Night crawler optimization (ENO) algorithm can be applied to other problems in Power system optimization and control. Then the validity of the algorithms can be tested in large systems and sequentially it can be applied to practical systems.

\section{Nomenclature}

OBF- Minimization of the Objective function.

$\mathrm{L}$ and $\mathrm{M}$ - control and dependent variables of the optimal reactive power problem

r- Consist of control variables

$\left(Q_{c}\right)$ - Reactive power compensators

$\mathrm{T}$ - Dynamic tap setting of transformers

$\left(V_{g}\right)$ - Level of the voltage in the generation units

$\mathrm{u}$-consist of dependent variables

$P G_{\text {slack }}$ - Slack generator

$V_{L}$ - Voltage on transmission lines

$Q_{G}$ - Generation unit's reactive power

$S_{L}$. Apparent power

NTL- Number of transmission line indicated by conductance of the transmission line between the $i^{\text {th }}$ and $j^{\text {th }}$ buses, $\emptyset_{i j}$. Phase angle between buses $\mathrm{i}$ and $\mathrm{j}$ $V_{L k}$-Load voltage in $k^{t h}$ load bus

$V_{L k}^{\text {desired }}-$ Voltage desired at the $k^{\text {th }}$ load bus,

$Q_{G K}-$ Reactive power generated at $k^{\text {th }}$ load bus generators,

$Q_{K G}^{L i m}$ - Reactive power limitation,

$N_{L B}$ and $\mathrm{Ng}$ - number load and generating units

$\mathrm{Tt}$ - Transformer tap

Gen volt- Generator Voltage

\section{References}

[1] Abril I.P., Quintero J.A.G. VAR Compensation by sequential quadratic programming. IEEE Trans. Power Syst., 18 (1) (2003), pp. 36-41

[2] M. R. Bjelogrlic, M. S. Calovic, B. S. Babic. (1990). Application of Newton's optimal power flow in voltage/reactive power control. IEEE Trans Power System, vol. 5, no. 4, pp. 1447-1454.

[3] S. Granville.(1994). Optimal reactive dispatch through interior point methods. IEEE Transactions on Power System, vol/issue: 9(1), pp. 136-146. http://dx.doi.org/10.1109/59.317548
[4] N. Grudinin.(1998). Reactive power optimization using successive quadratic programming method. IEEE Transactions on Power System, vol/issue: 13(4), pp. 1219-1225. http://dx.doi.org/10.1109/59.736232.

[5] Edalatpanah, SA. (2020). A Direct Model for Triangular Neutrosophic Linear Programming. International Journal of Neutrosophic Science, Vol. 1, No. 1, PP. 19-28, 2020, 1. 14-23. 10.5281/zenodo.3679499.

[6] Ebeed, M.; Alhejji, A.; Kamel, S.; Jurado, F.(2020). Solving the Optimal Reactive Power Dispatch Using Marine Predators Algorithm Considering the Uncertainties in Load and Wind-Solar Generation Systems. Energies, 13,4316,https://doi.org/10.3390/e n13174316

[7] Li, Jian ; Wang, Ni ; Zhou, Dao ; Hu, Weihao ; Huang, Qi ; Chen, Zhe ; Blaabjerg, Frede.(2020) Optimal reactive power dispatch of permanent magnet synchronous generator-based wind farm considering levelised production cost minimisation. In: Renewable Energy.; Vol. 145. pp. 1-12.

[8] Yasir Muhammad, Rahimdad Khan, Muhammad Asif Zahoor Raja, Farman Ullah, Naveed Ishtiaq Chaudhary, Yigang He (2020). Solution of optimal reactive power dispatch with FACTS devices: A survey, Energy Reports, Volume 6, Pages 22112229, https://doi.org/10.1016/j.egyr.2020.07.030

[9] Barakat, A. F., El-Sehiemy, R. A.-A., \& Elsaid, M. (2020). Close Accord on Particle Swarm Optimization Variants for Solving Non-Linear Optimal Reactive Power Dispatch Problem. International Journal of Engineering Research in Africa, 46, 88-105.

https://doi.org/10.4028/www.scientific.net/jera.46.88

[10]Z. Sahli, A. Hamouda, A. Bekrar, and D. Trentesaux (2014). "Hybrid PSO-tabu search for the optimal reactive power dispatch problem," in Proceedings of the IECON 2014-40th Annual Conference of the IEEE Industrial Electronics Society, Dallas, TX, USA, November 2014.

[11] S. Mouassa, T. Bouktir, and A. Salhi (2017). Ant lion optimizer for solving optimal reactive power dispatch problem in power systems. Engineering Science and Technology, an International Journal, vol. 20, no. 3, pp. 885-895, 2017.

[12] B. Mandal and P. K. Roy (2013). Optimal reactive power dispatch using quasi-oppositional teaching learning based optimization. International Journal of Electrical Power \& Energy Systems, vol. 53, pp. 123-134.

[13] H. Khazali and M. Kalantar (2011). Optimal reactive power dispatch based on harmony search algorithm. International Journal of Electrical Power \& Energy Systems, vol. 33, no. 3, pp. 684-692.

[14] H. V. Tran, T. V. Pham, L. H. Pham, N. T. Le, and T. T. Nguyen (2019). Finding optimal reactive power dispatch solutions by using a novel improved stochastic fractal search optimization algorithm," Telecommunication Computing Electronics and Control, vol. 17, no. 5, pp. 2517-2526. 
[15] J. Polprasert, W. Ongsakul, and V. N. Dieu (2016). Optimal reactive power dispatch using improved pseudo-gradient search particle swarm optimization. Electric Power Components and Systems, vol. 44, no. 5, pp. 518-532, 2016.

[16] Thanh Long Duong, Minh Quan Duong, Van-Duc Phan , Thang Trung Nguyen, (2020). Optimal Reactive Power Flow for Large-Scale Power Systems Using an Effective Metaheuristic Algorithm. Hindawi Journal of Electrical and Computer Engineering, Volume 2020, Article ID 6382507, 11 pages https://doi.org/10.1155/2020/6382507.

[17] Muhammad, Yasir \& Khan, Rahimdad \& Raja, Muhammad Asif Zahoor \& Ullah, Farman \& Chaudhary, Naveed Ishtiaq \& He, Yigang. (2020). Solution of optimal reactive power dispatch with FACTS devices: A survey. Energy Reports. 6. 22112229. 10.1016/j.egyr.2020.07.030.

[18] A. Mukherjee and V. Mukherjee (2015). Solution of optimal reactive power dispatch by Chaotic Krill Herd algorithm. IET Generation, Transmission \& Distribution, vol. 9, no. 15, pp. 2351-2362.

[19]MATPOWER 4.1 IEEE 30-bus and 118-bus test system, http://www.pserc.cornell.edu/matpower.

[20] Illinois Center for a Smarter Electric Grid (ICSEG). Available online: https://icseg.iti.illinois.edu/ieee30-bussystem/ (accessed on 25 February 2019).

[21]Dai, C., W. Chen, Y. Zhu and X. Zhang (2009). Seeker optimization algorithm for optimal reactive power dispatch. IEEE T. Power Syst., 24(3): 12181231.

[22] Subbaraj, P. and P.N. Rajnarayan (2009). Optimal reactive power dispatch using self-adaptive real coded Genetic algorithm. Electr. Power Syst. Res., 79(2): 374-38.

[23] Pandya, S. and R. Roy (2015). Particle swarm optimization based optimal reactive power dispatch. Proceeding of the IEEE International Conference on Electrical, Computer and Communication Technologies (ICECCT), pp: 1-5.

[24] Ali Nasser Hussain, Ali Abdulabbas Abdullah and Omar Muhammed Neda, (2018). Modified Particle Swarm Optimization for Solution of Reactive Power Dispatch. Research Journal of Applied Sciences, Engineering and Technology 15(8): 316-327, 2018 DOI:10.19026/rjaset.15.5917.

[25] Vishnu, Mini, Sunil (2020). An Improved Solution for Reactive Power Dispatch Problem Using Diversity-Enhanced Particle Swarm Optimization. Energies. 13. 2862. Pp 2-21, 2020 10.3390/en13112862. 